\title{
Supercritical fluid processing of natural based polymers doped with ionic liquids
}

\author{
M. Martins ${ }^{\mathrm{a}, \mathrm{b}}$, Rita Craveiro ${ }^{\mathrm{c}}$, Alexandre Paiva ${ }^{\mathrm{c}}$, Ana Rita C. Duarte ${ }^{\mathrm{a}, \mathrm{b}, *}$, Rui L. Reis ${ }^{\mathrm{a}, \mathrm{b}}$ \\ a 3B's Research Group - Biomaterials, Biodegradable and Biomimetic, University of Minho, Headquarters of the European Institute of Excellence on Tissue Engineering and \\ Regenerative Medicine, Avepark 4806-909 Taipas, Guimarães, Portugal \\ ' ICVS/3B's PT Government Associated Laboratory, Braga, Guimarães, Portugal \\ ${ }^{\mathrm{c}}$ REQUIMTE/CQFB, Departamento de Química, Faculdade de Ciências e Tecnologia, Universidade Nova de Lisboa, 2829-516 Caparica, Portugal
}

\section{H I G H L I G H T S}

- Modification and processing of natural based materials following a green chemistry approach.

- Natural based polymeric foams doped with ionic liquids as hybrid materials with advanced properties.

- Characterization of the role of ionic liquids in supercritical fluid foaming process.

- Preparation of new supports for catalysis, chromatography, micro extraction.

\section{A R T I C L E I N F O}

\section{Article history:}

Received 12 June 2013

Received in revised form 11 October 2013

Accepted 28 November 2013

Available online 4 December 2013

\section{Keywords:}

Ionic liquids

Supercritical fluid foaming

Polymer processing

Starch

Poly (lactic acid)

Carbon dioxide

\begin{abstract}
A B S T R A C T
Some approaches have been developed in our group to investigate the role of novel ionic liquids as process and property modifiers of natural-based polymers. In our previous work, we proposed the use of ionic liquids as plasticizing agents for the creation of porous structures from a semi-crystalline natural-based polymer. The current work intended to complement the previous studies, evaluating the ability of ionic liquid (IL) to plasticize polymers such as blends of starch-poly-lactic acid (SPLA) and its effect on supercritical fluid foaming process (SCF) and providing more insights on the mechanisms involved. For this purpose, blends of starch with poly (lactic) acid, with different ratios of starch and poly-lactic acid of 50:50 and 30:70 were modified and processed using 1-butyl-3-methylimidazolium chloride ([bmim]Cl). Supercritical fluid foaming was studied at different soaking times $(1,3$ and $6 \mathrm{~h}$ ) using carbon dioxide at $20.0 \mathrm{MPa}$ and $40^{\circ} \mathrm{C}$. The blends were characterized by different techniques, such as infra-red spectroscopy, differential scanning calorimetry and compression and tensile mechanical analysis. The morphology of the foamed structures was analyzed by scanning electron microscopy and micro-computed tomography. The results suggest that after $3 \mathrm{~h}$ of soaking time an equilibrium state of carbon dioxide into the bulk samples is attained, yielding structures with $6 \%$ and $15 \%$ of porosity, for SPLA70 and SPLA50 respectively. The solubility of carbon dioxide within the matrices was studied for the same conditions and the results demonstrate a higher sorption degree in the samples doped with ionic liquid. Sorption and desorption diffusion coefficients of supercritical $\mathrm{CO}_{2}$ in the SPLA matrix were determined for the raw polymer and for the SPLA doped with [bmim] $\mathrm{Cl}$. It was found that the lower desorption diffusion coefficients are related with the higher porosity obtained by the foaming process.
\end{abstract}

(C) 2013 Published by Elsevier B.V.

\section{Introduction}

In recent years, there has been a marked increasing interest in biodegradable polymers due to their obvious environment-friendly

\footnotetext{
* Corresponding author at: 3B's Research Group- Biomaterials, Biodegradable and Biomimetic, University of Minho, Headquarters of the European Institute of Excellence on Tissue Engineering and Regenerative Medicine, Avepark, 4806-909 Taipas, Guimarães, Portugal. Tel.: +351 253510 900; fax: +351 253510909.

E-mail address: aduarte@dep.uminho.pt (A.R.C. Duarte).
}

properties when compared to conventional petroleum derived polymeric materials $[1,2]$. Starch is a natural polymer which possesses many unique properties and is one of the most promising biodegradable polymers, readily available from different sources, such as maize, corn or potato. The flexibility of starch based materials can be improved by some approaches, for example blending this polymer with others. Blends of starch with synthetic polyesters have been reported in the literature for different applications that go from food industry and agriculture to biomedical field [3]. Poly-lactic acid is one of the polymers which can be blended 
with starch and is the product that at the present time has one of the highest potentials due to its availability in the market and its low price [4]. Furthermore, its biodegradation does not present any toxicological concerns. Blends of starch and PLA, when compared to starch, present a more hydrophobic character, lower water permeability and improved mechanical properties [5]. Processing natural-based materials still presents, however, major challenges in polymer science. The combination of supercritical technology with ionic liquids has been suggested as a green approach to overcome the drawbacks of conventional polymer processing techniques [6]. Carbon dioxide is the most commonly used fluid due to its non-toxic properties and to the low operation temperature involved in supercritical processes $\left(T \mathrm{c}=31^{\circ} \mathrm{C}\right.$ and $P c=73$ bar) [7]. Ionic liquids (ILs), on the other hand, are organic molten salts, that typically have extremely low volatility and high functionality. ILs are powerful solvents widely used due to their chemical and thermal stability, and high ionic conductivity properties. Although ILs are usually considered as green solvents, there are some drawbacks regarding its use. Besides having a certain level of toxicity, heat and mass transfer problems as well as phase changes may occur in their synthesis. Furthermore, the effect of water content on ILs, can strongly affect their viscosity. Nonetheless, the variety of ionic liquid structures resulting from the numerous possible combinations of cations and anions, may lead in the future to the synthesis of greener and biodegradable solvents [8]. The dissolution of natural polymers in ionic liquids as well as the plasticizing effect of ionic liquids has been reported in different studies. In particular [bmim]Cl, which was the IL studied in this work has been reported to be a good solvent for cellulose [9], chitin and chitosan [10] and a plasticizing agent of starch [11]. Doping a natural-based polymer with an ionic liquid has been described in literature as strategy to enhance polymer foaming [12]. In the reported work a blend of starch and poly- $\varepsilon$-caprolactone was studied and the results suggest the plasticizing ability of the ionic liquid [13]. In the present work we evaluate the characteristics of SPLA dopped with an ionic liquid and the effect of the presence of the IL on supercritical carbon dioxide foaming of the polymer. One of the great advantages of working under supercritical media is the possibility of modifying the morphological and functional properties of polymers by swelling, furthermore, carbon dioxide at high pressure can be impregnated in the polymeric matrix due to the molecular forces that are established between the two species [14]. The supercritical fluid foaming relies on the ability of carbon dioxide to act as a temporary plasticizing agent, lowering the glass transition temperature $\left(T_{\mathrm{g}}\right)$ of semi-crystalline polymers $[15,16]$. The reduction of the $T_{\mathrm{g}}$ is a thermodynamic effect highly dependent on the interactions between polymer-carbon dioxide. Stronger interactions will enhance the $T_{\mathrm{g}}$ depression and polymer chain flexibility.

The behavior of different classes of polymers in supercritical carbon dioxide, particularly the manipulation of their physical properties and their selective control has become an area of interest in polymer synthesis and processing. The knowledge of the solubility and diffusion coefficients of carbon dioxide in the polymeric matrix is important for the determination of the best operating parameters and the understanding of the process. Different methods have been reported in the literature for the determination of these parameters and the most commonly used are the use of a quartz micro-balance [15] or a gravimetric or barometric method [16,17]. In situ spectroscopic techniques have also been reported to be a valuable tool for the quantification of the weight percentage of carbon dioxide dissolved in the polymeric matrix $[18,19]$. In this work, a gravimetric method was used to determine the sorption degree and diffusion coefficients of carbon dioxide in the raw SPLA samples and in the samples doped with ionic liquid.

\section{Material and methods}

\subsection{Materials}

The polymers used on this study were based on a blend of corn starch and poly (lactic acid) with different compositions of poly (lactic acid) $50 \mathrm{wt} \%$ (SPLA50) and $70 \mathrm{wt} \%$ (SPLA70). These polymers were obtained from Novamont. The ionic liquid used was 1-butyl-3-methylimidazolium chloride ([bmim]Cl) obtained from Sigma Aldrich. Carbon dioxide (99.998 mol\%) was supplied by Air liquide. All materials were used without any additional purification.

\subsection{Sample preparation}

SPLA samples blended with IL were prepared by compression moulding using a Moore Hydraulic Press (UK) at $80^{\circ} \mathrm{C}$ and $6 \mathrm{MPa}$ for $15 \mathrm{~min}$. Disc shape like samples of SPLA 50 and SPLA 70, with $10 \mathrm{wt} \%$ [bmim] Cl were prepared using steel rings $(12 \times 2 \mathrm{~mm})$ as mould. Table 1 summarizes the materials prepared.

\subsection{Supercritical fluid foaming}

The porous matrixes were prepared by supercritical fluid foaming (SCF) at $20.0 \mathrm{MPa}$ and $40{ }^{\circ} \mathrm{C}$ for different soaking times (1, 3 and $6 \mathrm{~h})$. The samples were loaded in the high pressure vessel, heated to the desired temperature by using an electric thin band heater (OGDEN) connected to a temperature controller. Carbon dioxide was pumped into the vessel using a high pressure piston pump (P-200A Thar Technologies) until the operation pressure was attained and the pressure inside the vessel was measured with a pressure transducer. The system was closed in order to promote the foaming of the matrixes. Afterwards, the system was slowly depressurized.

\section{Characterization}

\subsection{Differential scanning calorimetry (DSC)}

The DSC experiments were performed using DSC Q100 V9.8 Build 296 apparatus. The samples were placed in aluminum pans and heated at a rate of $10^{\circ} \mathrm{C} / \mathrm{min}$ from 20 to $220^{\circ} \mathrm{C}$, cooled to $20^{\circ} \mathrm{C}$ and heated at $5^{\circ} \mathrm{C} / \mathrm{min}$ until $200^{\circ} \mathrm{C}$. Standard calibrations were performed using indium leads.

\subsection{Compressive and tensile mechanical analysis}

Compressive and tensile mechanical analysis of the materials produced were measured using an INSTRON 5540 (Instron Int. Ltd., High Wycombe, UK) universal testing machine with a load cell of $1 \mathrm{kN}$.

Compression testing was carried out at a crosshead of $2 \mathrm{~mm} \mathrm{~min}^{-1}$, until a maximum reduction in sample weight of $60 \%$. The compressive modulus is defined as the initial linear modulus on the stress/strain curves. In tensile mode, the dimensions of the specimens used were $60 \mathrm{~mm}$ of length, $1 \mathrm{~mm}$ width and $3 \mathrm{~mm}$

Table 1

Summary of the matrices prepared.

\begin{tabular}{llll}
\hline Polymer & Ionic liquid & IL concentration (wt\%) & Reference \\
\hline SPLA 50 & - & - & SPLA50 \\
SPLA 70 & - & - & SPLA70 \\
SPLA 50 & {$[$ bmim]Cl } & 10 & SPLA50 10Cl \\
SPLA 70 & {$[$ bmim]Cl } & 10 & SPLA70 10Cl \\
\hline
\end{tabular}


of thickness. The load was placed midway between the supports with a span (L) of $30 \mathrm{~mm}$. The crosshead speed was 1:5 $\mathrm{mm} \mathrm{min}^{-1}$. For each condition the specimens were loaded until core break. The data presented is the result of the average of at least five measurements.

\subsection{Infrared spectroscopy (FTIR-ATR)}

The infrared spectra of SPLA50 and SPLA70 with and without IL was obtained in transmittance mode, using a Shimadzu-IR Prestige 21 spectrometer equipped with an attenuated total reflection (ATR) system in spectral region of $4400-800 \mathrm{~cm}^{-1}$ with a resolution of $4 \mathrm{~cm}^{-1}$ for 32 scans.

\subsection{Scanning electron microscopy (SEM)}

Porous matrixes prepared were observed by a Leica Cambridge S360 Scanning Electron Microscope (SEM). Cross sections of the specimens were examined after fracturing in liquid nitrogen. The matrices were fixed by mutual conductive adhesive tape on aluminum stubs and covered with gold palladium using a sputter coater.

\subsection{Micro-computed tomography (micro-CT)}

The morphological structure and the calculation of the morphometric parameters that characterize the samples were evaluated by micro-computed tomography (micro-CT) using Scanco 20 equipment (Skyscan 1702, Belgium) with penetrative X-rays of $45 \mathrm{keV}$ and $222 \mu \mathrm{A}$ for SPLA70 and $53 \mathrm{keV}$ and $189 \mu \mathrm{A}$ for SPLA50, in high resolution mode with a pixel size of $14 \mu \mathrm{m}$ and $1.5 \mathrm{~s}$ of exposure time. A CT analyzer (v1.5.1.5, SkyScan) was used to calculate the parameters from the $2 \mathrm{D}$ images of the matrices.

\subsection{Sorption measurements}

The solubility of carbon dioxide in the polymeric matrixes was measured by a gravimetric procedure similar to that described by Berens et al. [20]. Sorption measurements of carbon dioxide were carried out at the same conditions of the foaming experiments, i.e., $40^{\circ} \mathrm{C}$ and $20.0 \mathrm{MPa}$ for 1,3 and $6 \mathrm{~h}$. Briefly, the sample is weighted and loaded into a high-pressure vessel and heated in a thermostatic water bath to the desired temperature $\left( \pm 1^{\circ} \mathrm{C}\right)$. Carbon dioxide is liquefied in a refrigerator containing a water/ethylene glycol solution, before being pumped with an HPLC pump (maximum flow $100 \mathrm{~mL} / \mathrm{min}$; KNAUER preparative Pump 1800, Berlin, Germany), until the desired pressure is attained. The pressure is measured with a pressure transducer within $\pm 0.01 \mathrm{MPa}$. At the end of the experiment, the vessel is rapidly depressurized and the sample is transferred to a balance to record weight changes during desorption at atmospheric pressure, during $1 \mathrm{~h}$. A schematic representation of the experimental apparatus is presented in Fig. 1.

According to a Fickian diffusion the amount of $\mathrm{CO}_{2}$ dissolved in the polymer follows a linear relationship with the square root of time. Therefore, the amount of $\mathrm{CO}_{2}$ dissolved in the polymer for each sorption time experiment is taken by the linear regression of desorption data at time zero.

\subsection{Statistical analysis}

Statistical analysis of the data was conducted using IBM SPSS Statistics version 20 software. Shapiro-Wilk test was employed to evaluate the normality of the data sets. The results obtained in this work follow a normal distribution. In this case, one way ANOVA coupled with the Bonferroni post hoc test was used to determine statistical significant differences. Differences between the groups with $p<0.05$ were considered to be statistically significant.

\section{Discussion}

Blending is the easier process to associate different polymers together providing a powerful route to obtain materials with improved property performances [21]. Depending on the materials and the processing system used, various structures can be obtained. Doping the polymeric blend with a plasticizer may further enhance their processability, flexibility or ductility. Thus the advances in polymer science may greatly benefit from the study of polymeric blends.

In a first approach we evaluated the dispersion of $10 \mathrm{wt} \%$ and $30 \mathrm{wt} \%$ [bmim]Ac in SPLA50 and SPLA70, however the mixtures were not homogenous and a phase separation was observed. This fact allows us to infer that the interactions between SPLA and [bmim]Ac are not favorable to the formation of a compatible blend. The same strategy was adopted changing the ionic liquid anion from acetate to chloride. In this case, we observed that in presence of $10 \mathrm{wt} \%$ of [bmim] Cl, it was possible to obtain a homogenous mixture. The analysis carried out to understand the interactions between this IL and the polymeric blends were performed in compressed moulded samples doped with $10 \mathrm{wt} \%$ [bmim]Cl.

\subsection{FTIR analysis}

The analysis of the interactions between ionic liquid and polymer were firstly assessed by infra-red spectroscopy, which has proved to be an excellent analytical technique for screening and

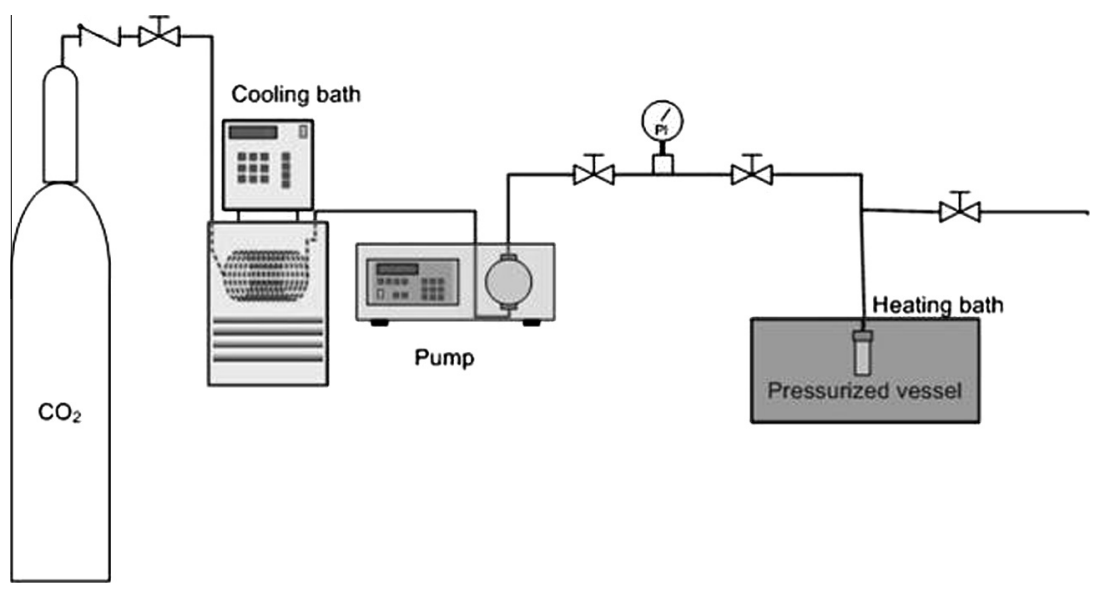

Fig. 1. Schematic representation of the experimental apparatus used for the sorption measurements. 
profiling polymer samples. In this work, the chemical interactions between SPLA50 and SPLA70 and [bmim]Cl were examined through FTIR-ATR. The assignments of the main adsorption bands of starch, poly(lactic-acid) and [bmim]Cl are indicated in Table 2. [22-24]

The spectra of the compressed moulded blends are shown in Fig. 2 and the differences observed in the spectra indicate changes in chemical structure upon blending.

The differences observed between the spectra of SPLA50 and SPLA70, are justified by the different composition of starch and PLA present in blends [25] and these correspond mainly to a higher intensity of the characteristic peak of PLA. In case of SPLA50 and SPLA70 blended with [bmim]Cl, it was possible to detect changes in the peak at $1040 \mathrm{~cm}^{-1}$ attributed to $\mathrm{CH}_{3}$ rocking groups of PLA. This is due to the interactions between the ionic liquid and PLA, which is in agreement with the data found in literature [23]. More noticeable is the increase in intensity of the characteristic peak of starch at $1080 \mathrm{~cm}^{-1}$, correspondent to the $\mathrm{C}-\mathrm{O}-\mathrm{H}$ group, suggesting that the interaction of [bmim] $\mathrm{Cl}$ is stronger with starch than with PLA, corroborating previously reported data [11]. The broad peak in range $3000-300 \mathrm{~cm}^{-1}$ is noticeable higher in case of blends with ionic liquid, demonstrating an increase in the hydrogen bounds, which confirm the interactions with SPLA and [bmim]Cl [13].

\subsection{DSC analysis}

Thermal characterization of the blends was performed by differential scanning calorimetry analysis. Table 3 presents the values determined for the $T_{\mathrm{g}}$, melting temperature and crystallinity of the

Table 2

FTIR characteristic peaks starch, poly(lactic-acid) and [bmim]Cl.

\begin{tabular}{llll}
\hline Material & Wavenumber $\left(\mathrm{cm}^{-1}\right)$ & Characteristic peak & Reference \\
\hline Starch & $1080 ; 1362-1338$ & $\mathrm{C}-\mathrm{O}$ stretching & \\
& 1413 & $\mathrm{O}-\mathrm{H}$ bending & {$[24]$} \\
& 1456 & $\mathrm{CH}_{2}$ bending & $\mathrm{CH}_{2}$ rocking \\
& 925 & $\mathrm{CH}_{3}$ rocking & \\
Poly(lactic acid) & $1044 ; 1094 ;$ & $\mathrm{C}-\mathrm{COO}$ stretching & \\
& $1128 ; 1184$ & $\mathrm{CH}$ bending & \\
& $1362-1356$ & $\mathrm{C}=\mathrm{O}$ bending & \\
& 1455 & & \\
{$[$ bmim $] \mathrm{Cl}$} & 1751 & $\mathrm{C}=\mathrm{O}$ acetate carboxylate & {$[26]$} \\
& 1578 & $\mathrm{O}-\mathrm{H}$ stretching & \\
\hline
\end{tabular}

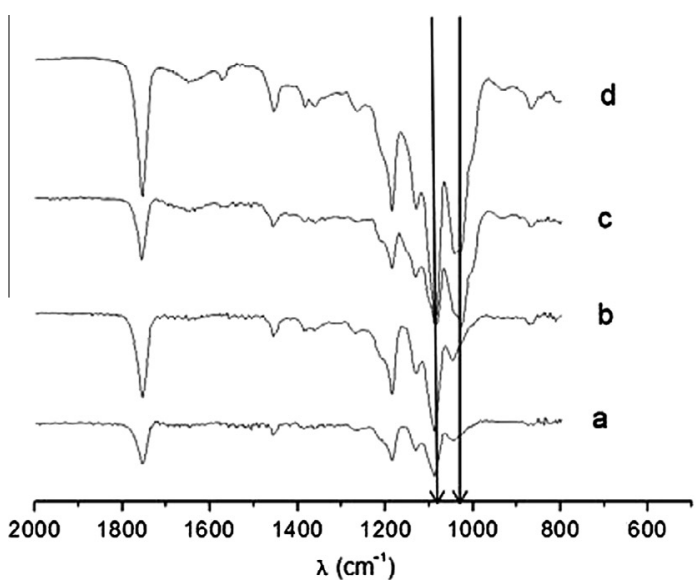

different samples. The DSC thermograms of SPLA50 and SPLA70, represented in Fig. 3 revealed two overlapping processes in the endothermic melting peaks which may be a result of different crystal structures of PLA present in blends. The melting peak of SPLA50 was lower than SPLA70, which may be due to the higher weight fraction of starch in the blend. In the presence of ionic liquid the thermograms show a single endothermic melting peak, which lead us to conclude that IL modifies the crystalline structure of the raw material. These observations were valid for both SPLA50 $10 \mathrm{Cl}$ and SPLA70 $10 \mathrm{Cl}$. Regarding the $T_{\mathrm{g}}$ of the polymers, observed at 58.0 and $59.4{ }^{\circ} \mathrm{C}$ for SPLA50 and SPLA70 respectively, are consistent with the data found in literature [25]. The decrease in the $T_{\mathrm{g}}$ observed for the SPLA blends doped with ionic liquid suggests that [bmim] $\mathrm{Cl}$ can act as a plasticizing agent, decreasing the $T_{\mathrm{g}}$ value by almost $10{ }^{\circ} \mathrm{C}$ in the case of SPLA70. These results are statistically significant.

The determination of the crystallinity of the samples is straightforward and an easy way to obtain information on the properties of semi-crystalline polymers. The degree of PLA crystallinity $\left(X_{c}\right)$ can be determined by the thermal spectra, quantifying the heat associated with melting of the polymer, from Eq. (1):

$X_{c}=\left(\Delta H_{m} /\left(\Delta H_{m}^{0} * w\right)\right) * 100$

where $\Delta H_{m}$ is the specific melting enthalpy of the sample, $\Delta H_{m}^{0}$ is the melting enthalpy of $100 \%$ crystalline of poly(lactic)acid $(93 \mathrm{~J} / \mathrm{g}$ ) [26] and $w$ is the weight fraction of PLA in the blend, which is

Table 3

Properties of polymeric blends obtained by DSC results $\left(T_{\mathrm{g}}\right.$ - glass transition temperature, $T_{\mathrm{m}}$ - melting temperature).

\begin{tabular}{llll}
\hline Samples & $T_{\mathrm{g}}\left({ }^{\circ} \mathrm{C}\right)$ & $T_{\mathrm{m}}\left({ }^{\circ} \mathrm{C}\right)$ & $X_{\mathrm{c}}(\%)$ \\
\hline SPLA 50 & $58.0 \pm 0.2$ & $157.8 \pm 0.2$ & $31.3 \pm 0.5$ \\
SPLA50 10Cl & $57.1 \pm 0.9$ & $150.6 \pm 3.6$ & $18.9 \pm 1.1$ \\
SPLA70 & $59.4 \pm 0.3$ & $155.5 \pm 7.6$ & $42.2 \pm 0.4$ \\
SPLA70 10Cl & $52.4 \pm 2.4$ & $147.2 \pm 2.4$ & $34.1 \pm 0.5$ \\
\hline
\end{tabular}

Table 4

Mechanical properties of the materials determined in compression and tensile mode.

\begin{tabular}{llll}
\hline Sample & Compression & Tensile & \\
\cline { 3 - 4 } & $E(\mathrm{MPa})$ & $E(\mathrm{MPa})$ & Elongation at break $(\%)$ \\
\hline SPLA50 & $7.1 \pm 1.3$ & $624 \pm 76.5$ & $2.3 \pm 0.2$ \\
SPCL50 10Cl & $3.7 \pm 0.7$ & $142 \pm 51.7$ & $1.0 \pm 0.5$ \\
SPLA70 & $4.8 \pm 0.6$ & $502 \pm 27.6$ & $2.4 \pm 0.8$ \\
SPLA70 10Cl & $3.5 \pm 0.5$ & $354 \pm 61.5$ & $0.8 \pm 0.1$ \\
\hline
\end{tabular}

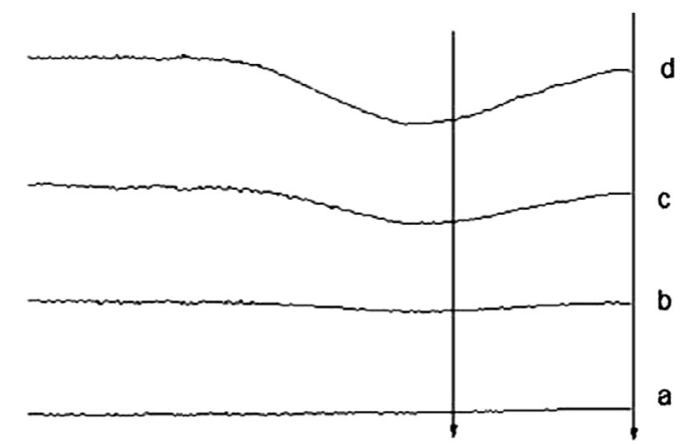

40003900380037003600350034003300320031003000

$\lambda\left(\mathrm{cm}^{-1}\right)$

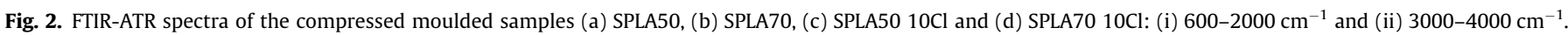




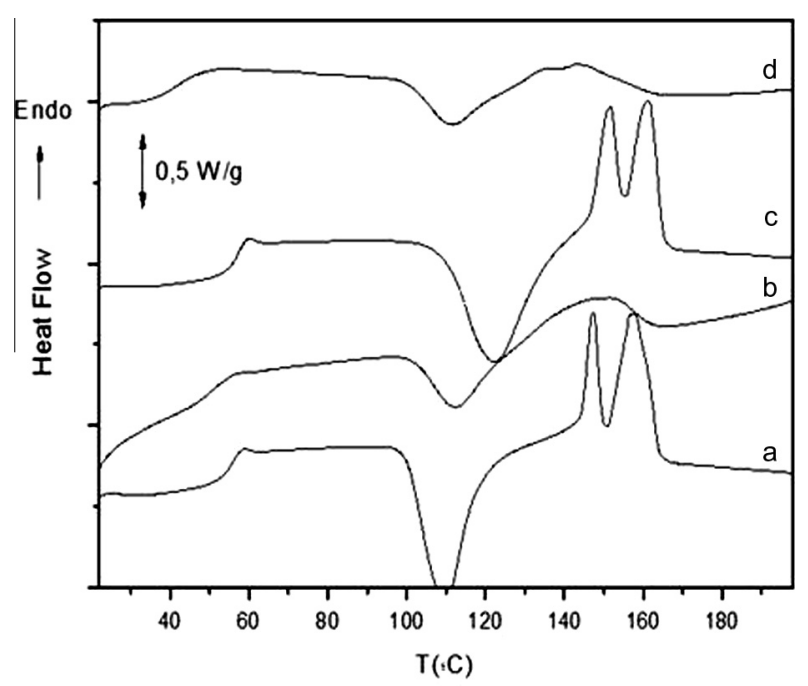

Fig. 3. DSC thermograms at $10{ }^{\circ} \mathrm{C} / \mathrm{min}$ for the blends under this study: SPLA50 (a), SPLA50 $10 \mathrm{Cl}$ (b), SPLA70 (c) and SPLA70 10Cl (d).

$50 \%$ and $70 \%$ in case of SPLA50 and SPLA70, respectively. The polymer crystallinity refers to the overall level of crystalline component in relationship to its amorphous component. From the results obtained it is clear the effect of ionic liquid on the crystallinity of both polymers.

\subsection{Compressive and tensile tests}

Mechanical tests were performed on the different compressed moulded samples in order to evaluate the effect of ionic liquid in the plasticization of polymer. Jacobsen and coworkers report the effect of different types of plasticizers on the mechanical properties of poly (lactic acid) and a decrease in the maximum tensile stress and in elasticity modulus was observed [27]. Fig. 4 represents the Young modulus of the polymeric samples calculated in compression and tensile mode.

From Fig. 4 and Table 4 we can observe that the mechanical properties of polymeric blends are greatly affected by the addition of a plasticizer, which may indicate an increase of the polymeric chain mobility. The Young modulus is statistically different in the case of raw material and in the presence of ionic liquid (Fig. 4(A) and (B)), confirming the ability of [bmim] $\mathrm{Cl}$ to increase chain mobility and promote the plasticization of the structure. The tensile tests revealed also lower elongation at break in presence of [bmim]Cl. This effect is much more pronounced in the case of SPLA50 samples, which confirms the observations from FTIR-ATR that suggested a stronger interaction between IL and starch. [bmim] Cl has been shown to be an efficient plasticizer of starch, allowing the production of thermoplastic starch by melt processing [11]. Sankri et al. refer in their work that the decrease in Young modulus is due to a reduction of hydrogen bonds between the starch chains in the presence of IL [11].

\subsection{Foaming process}

The development of porous degradable structures has received great attention for different applications, e.g., insulation foams, packaging and tissue engineering. A wide range of fields may benefit from novel lightweight materials with enhanced properties. SPLA and SPLA dopped samples with ionic liquids were foamed with supercritical carbon dioxide at $20.0 \mathrm{MPa}$ and $40{ }^{\circ} \mathrm{C}$. Cross-sections of the samples were analyzed by scanning electron microscopy and micro-computed tomography in order to evaluate the extent of the foaming process in the morphological parameters of the samples. In this experimental work different soaking times were studied in order to evaluate the effect of carbon dioxide diffusion in the morphological characteristics of the matrices prepared. When tissue engineering and biomedical applications are aimed there is the need to remove any residual ionic liquid present in the matrix. The ionic liquid used in this study can easily be leached out by immersing the materials in water or ethanol or by performing a conventional soxhlet extraction [28].

\subsubsection{Morphological analysis}

Visual analysis of the cross-section of the samples was carried out by scanning electron microscopy analysis. Fig. 5 shows the cross-section of the SPLA 50 and SPLA50 dopped with IL foamed after different soaking times.

The cross section of samples showed some morphological changes concerning porosity and pore size in presence of [bmim] $\mathrm{Cl}$. The results suggest that the presence of the plasticizing agent is essential for the enhancement of the foaming process. In fact the samples of SPLA did not present any significant differences when compared to the samples that were not foamed. However, a more quantitative analysis has to be carried out. Micro-computed tomography allows quantification at high resolutions of microstructural morphology of the inner structure of the matrices prepared. Fig. 6 shows the different 2D cross-sections and the effect of soaking time on the foaming process.

In presence of [bmim] $\mathrm{Cl}$, micro-CT images revealed that it is possible to obtain porous structures. This effect is more evident in case of SPLA50 than SPLA70 matrix. The soaking time on foaming process is an important parameter which affects the structures obtained. It is expected that with increasing soaking time, more carbon dioxide molecules will diffuse into the bulk of the samples, resulting in higher porosity. Quantitative data may be obtained from the mathematical analysis of the images obtained, in CTAn
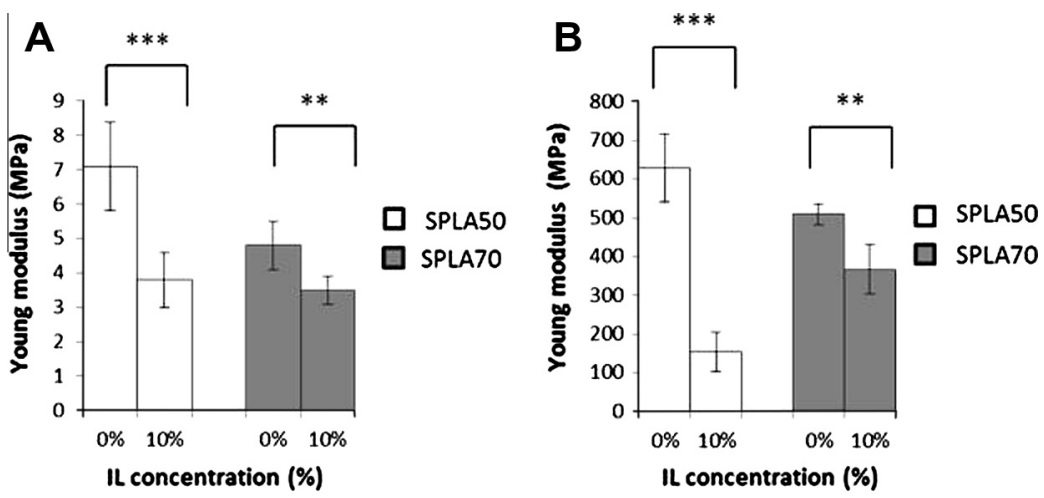

Fig. 4. Effect of [bmim] $\mathrm{Cl}$ on SPLA50 and SPLA70 mechanical properties in compressive (A) and tensile (B) mode. 


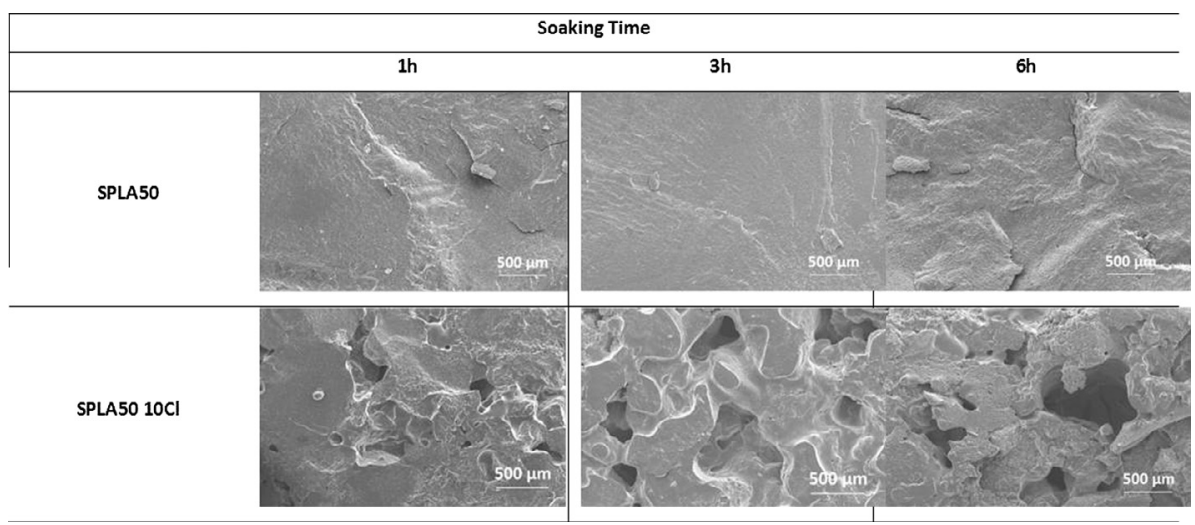

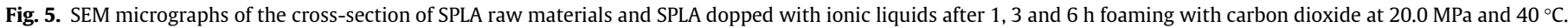

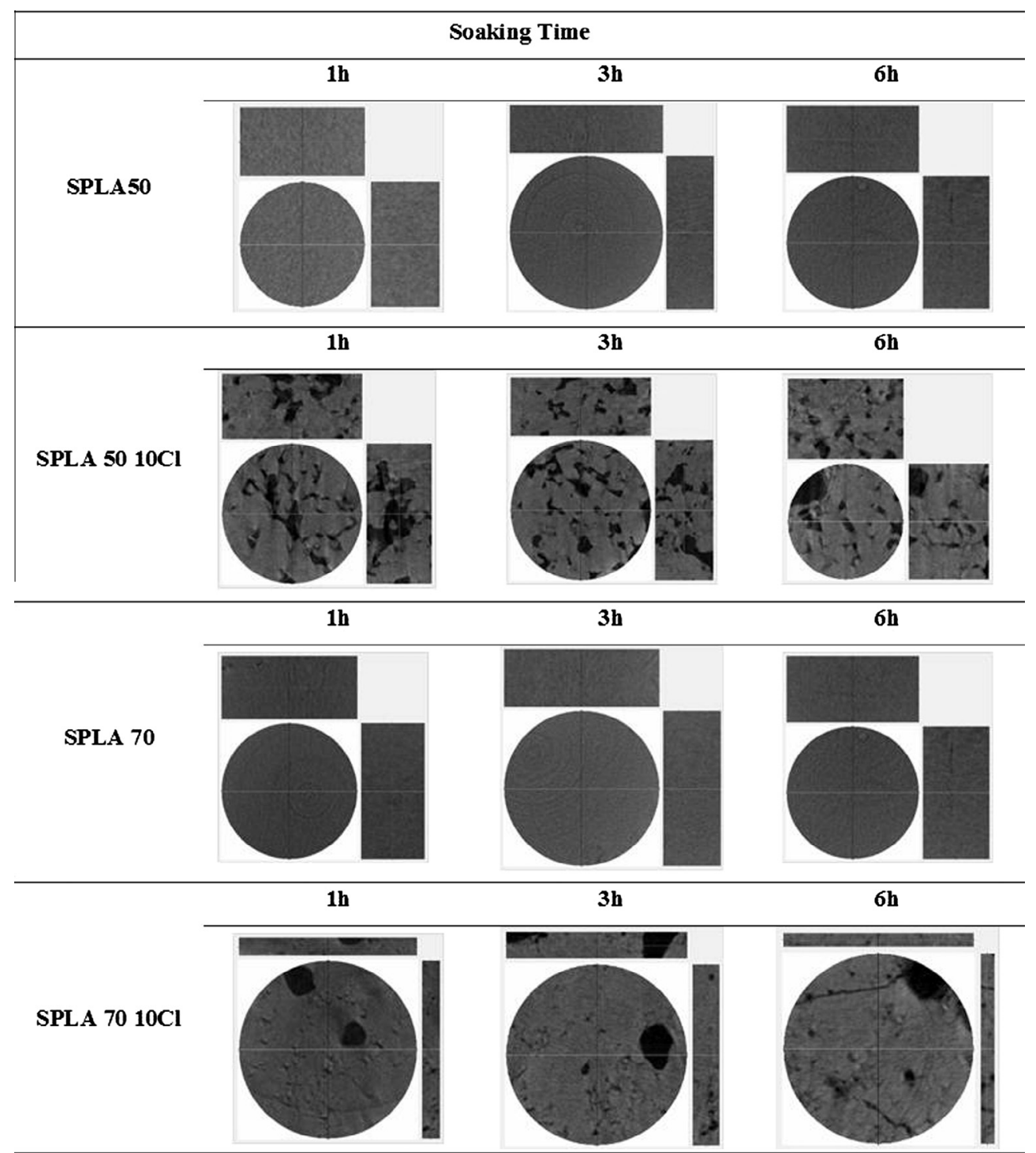

Fig. 6. Representative micro-CT $2 \mathrm{D}$ images of cross section of matrices prepared after supercritical fluid foaming at $20.0 \mathrm{MPa}$ and $40{ }^{\circ} \mathrm{C}$ for different soaking times.

software. Particularly important is the determination of the porosity of the samples, which was determined for all the samples, with and without IL after the different soaking periods. Fig. 7 illustrates the effect of the soaking time on the porosity of the samples, as well as the differences obtained between SPLA50 and SPLA70.
Statistically significant differences were observed when comparing the two polymers for all soaking times tested. Regarding the effect of soaking time on the porosity increase this was only observed in the case of SPLA $5010 \mathrm{Cl}$ for an increase from 1 to $3 \mathrm{~h}$ of exposure to carbon dioxide. 


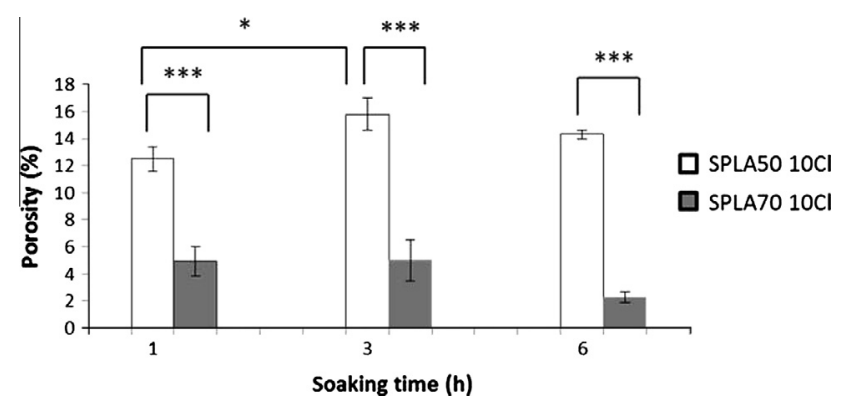

Fig. 7. Effect of soaking time on the porosity of the matrices prepared at $40{ }^{\circ} \mathrm{C}$ and $20 \mathrm{MPa}$.

Different mechanisms are involved in the gas foaming process. The solubility of carbon dioxide in the matrix controls the gas bubble nucleation and the porous structure formation. In this sense, favorable interactions between the polymer chains and gas enhance the foaming process. At the same time the inherent polymer crystallinity of the samples is also a parameter that greatly influences the foaming ability. In the case of semi-crystalline polymers, the crystal domains do not contribute to carbon dioxide sorption. Thermal analysis by DSC of raw and processed materials was carried out to verify the changes in the polymer crystallinity prior and after foaming process. The experimental results presented in Fig. 8, indicate that the soaking time is an important parameter which affects the crystallinity, promoting the decrease of polymer crystalline domains. The decrease of crystallinity was more noticeable when the ionic liquid was present in the blends. Moreover, it was possible to visualize a higher crystallinity on SPLA70 than SPLA50, as it would be expected due to the higher fraction of starch present in the blend. Liao and coworkers have discussed in their work the competitive effect of carbon dioxide sorption and $\mathrm{CO}_{2}$-induced crystallization [29]. The dissolved carbon dioxide within the matrix induces physical changes in the polymer, which are translated in different crystalline structures within the foamed polymer. According to our observations, the crystallinity of SPLA (both SPLA 50 and SPLA70) decreased with the exposure to carbon dioxide at high pressure, which may be explained by the rapid crystallization of the polymer after foaming due to the gas diffusion of the carbon dioxide out of the matrix. The fast crystallization does not promote the formation of highly ordered structures, rendering matrices with lower crystallinity.

On the other hand, the solubility of carbon dioxide in the polymeric blends controls the pore nucleation and structure formation.

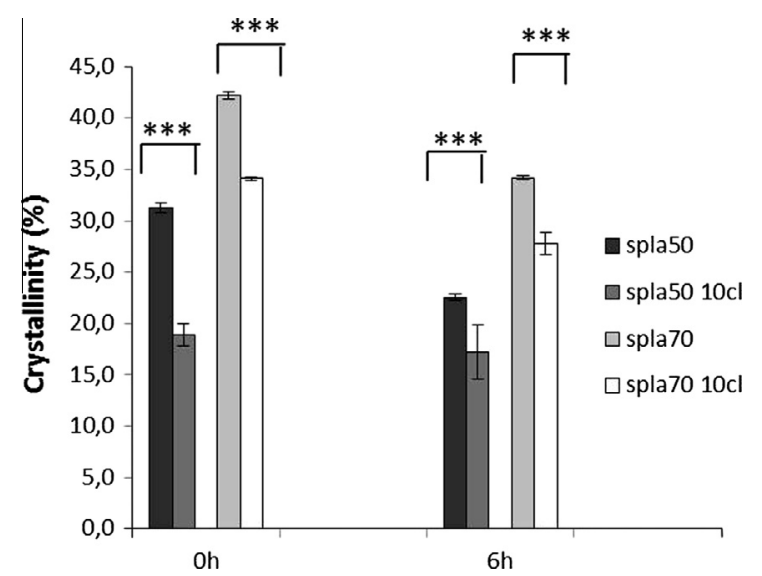

Fig. 8. Crystallinity of the different polymeric samples before and after foaming process.
Therefore, it is expected that the sorption degree of the matrices may be related with the porosity of the structures obtained. The determination of the amount of gas dissolved in the matrices was determined by a gravimetric method.

4.4.2. Carbon dioxide sorption measurements - mathematical analysis

The mathematical treatment of the polymers depends on whether the polymer is in the rubbery or glassy state that is, whether above or below its $T_{\mathrm{g}}$. When the diffusing substance causes extensive swelling of the polymer it exhibits an "anomalous" or "non-Fickian" behavior. In the case of the samples prepared, no extensive swelling of the matrices was observed, and hereafter, the mathematical analysis of the sorption measurements was performed following Fick's theory of diffusion through isotropic matrices $[30,31]$.

Fick's first law of diffusion is based on the hypothesis that the transfer rate of a diffusing substance through a unit of area of a section is proportional to the concentration gradient normal to that section, given by Eq. (2):

$J=-D \frac{\delta C}{\delta x}$

Where $D$ is the diffusion coefficient, $C$ is the concentration of the diffusing substance and $J$ is the flux.

The second law of diffusion is a differential equation solution of the first law, assuming one dimensional diffusion, i.e., the gradient of concentration only in one direction, along the $x$ axis, represented by Eq. (3):

$\frac{\partial C}{\partial t}=D\left(\frac{\partial^{2} C}{\partial x^{2}}\right)$

The simplified solution of Fick's second law (Eq. (4)) describing the time dependence of the diffusing material out of the sample, which in this case has a slab shape of thickness $l$, and considering that there is a uniform initial distribution and that the surface concentrations are equal is given by:

$\frac{M(t)}{M_{0}}=1-\frac{8}{\pi^{2}} e^{\left(\frac{-D_{S} \pi^{2} t}{l^{2}}\right)}$

For a constant sorption the apparent diffusion coefficient can be taken from the slope of the curve $\ln \left(1-\left(M(t) / M_{0}\right)\right)$ as a function of $\left(t / l^{2}\right)$, which is a straight line within the normal limits of the experimental error.

Sorption experiments were carried out for SPLA50 and SPLA70 in its raw form and in the presence of $10 \mathrm{wt} \%$ [bmim]Cl. For these experiments the sorption degree was obtained as the ratio between the mass of $\mathrm{CO}_{2}$ in the sample and the total mass (mass of $\mathrm{CO}_{2}$ plus mass of the polymer sample). To determine the maximum sorption degree, the sorption degree was plotted as a function of $t^{1 / 2}$ and the value for time zero was extrapolated and assumed to be the maximum sorption value (Fig. 9).

The apparent sorption and desorption coefficients of the different samples were calculated from Eq. (4), as previously described. The values for the maximum sorption degree and the sorption and desorption coefficients for all the studied SPLA samples are presented in Table 5 . The highest sorption degree was obtained for SPLA70 $10 \mathrm{Cl}$, with a value of $17.7 \%$. Nevertheless, it can be noted that for SPLA50 $10 \mathrm{Cl}$ the sorption degree value was $15.7 \%$. Thus, we can assume that although SPLA70 is more crystalline, the sorption of $\mathrm{CO}_{2}$ is not significantly affected by the higher content of PLA in the samples.

As expected the presence of IL increases the sorption degree in both SPLA70 and SPLA50 with an increase in the sorption value of as much as $6 \%$. 


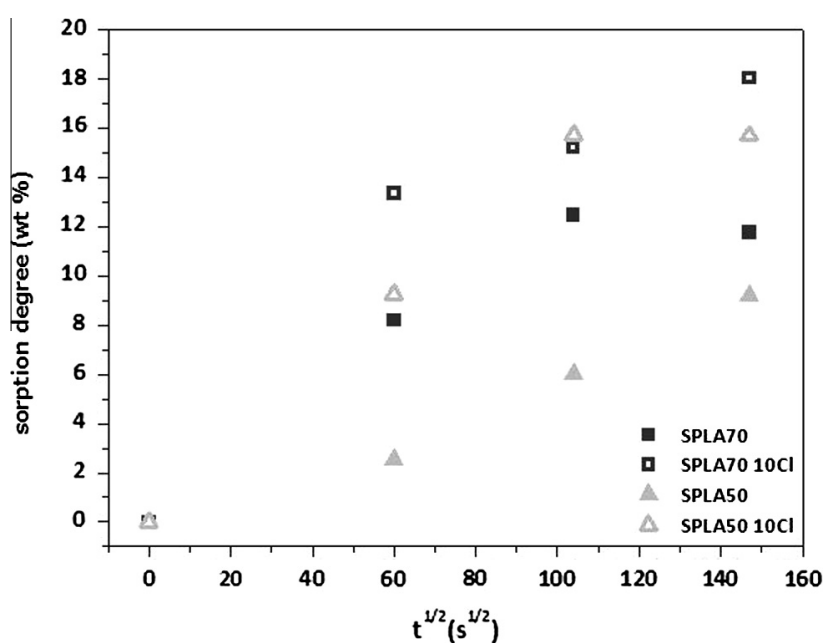

Fig. 9. Sorption curves for samples SPLA70, SPLA70 10Cl, SPLA50 and SPLA50 10Cl.

In Fig. 10 is represented the $\ln \left(M(t) / M_{0}\right)$ as a function of $t / l^{2}$ for the calculation of the sorption and desorption coefficients. The apparent sorption diffusion coefficient values were about 10 -fold higher in the presence of IL, when compared with the raw polymer. As previously reported [17] the apparent desorption diffusion coefficient is higher than the apparent sorption diffusion coefficient; this can be attributed to the fact that the desorption process, i.e., the release of $\mathrm{CO}_{2}$ from the polymer matrix, is faster than the sorption, since the polymeric chains present a higher mobility and are more flexible after exposure to $\mathrm{CO}_{2}$, confirming its plasticizing ability.

The lower desorption diffusion coefficient of SPLA50 regarding SPLA70 is in agreement with the previous foaming results. Due to the lower desorption diffusion coefficient, it is harder for $\mathrm{CO}_{2}$ to diffuse out of the polymer structure during decompression. Therefore the expansion effect is more evident for SPLA50 resulting in a higher foaming degree and consequently in a higher porosity.

\section{Conclusions}

In this work, we evaluated the plasticizing effect of [bmim] $\mathrm{Cl}$ on supercritical fluid foaming of two different natural-based semicrystalline polymeric blends, particularly SPLA50 and SPLA70. FTIR- ATR spectroscopy has shown interactions between the ionic liquid and the polymeric blend, particularly, the ionic liquid has stronger interactions with starch rather than with poly-lactic acid. According to the results of thermal analysis by DSC, it was possible to determine the decrease in $T_{\mathrm{g}}$ of SPLA/ILs blends, more patent in case of SPLA70 than SPLA50. [bmim]Cl could hereafter be considered as a plasticizing agent, decreasing the $T_{\mathrm{g}}$ of the blends and also decreasing the Young modulus of the matrices, which was demonstrated by either compression and tensile mechanical tests. Furthermore, the changes in polymer crystallinity were also determined. The presence of [bmim] $\mathrm{Cl}$ decreased the crystallinity of the samples, which may explain the enhancement of the foaming process by supercritical carbon dioxide, that increase from $0 \%$ to $14 \%$ in the case of SPLA50. From the experiments performed we can also conclude that the soaking time used in foaming process with [bmim] Cl is an important parameter, which has an impact in the porous structures obtained. Sorption experiments allowed the mathematical determination of the apparent sorption and desorption coefficients, which are in agreement with the presence of [bmim] $\mathrm{Cl}$ and supercritical carbon dioxide having a plasticizing effect on the polymeric blends, increasing chain mobility.

It was confirmed that the foaming effect is highly dependent on the mobility of the polymeric chains of the SPLA blend (related

Table 5

Sorption degree, apparent sorption and desorption coefficients for the different sorption experiments performed with SPLA samples.

\begin{tabular}{|c|c|c|c|c|c|c|}
\hline Sample & $T\left({ }^{\circ} \mathrm{C}\right)$ & $P(\mathrm{MPa})$ & Thickness (mm) & Max. sorption degree (\%) & Apparent sorption coeff. $\left(\mathrm{m}^{2} / \mathrm{s}\right)$ & Apparent desorption coeff. $\left(\mathrm{m}^{2} / \mathrm{s}\right)$ \\
\hline SPLA50 & 40 & 20.0 & 2 & 9.17 & $4.14 \mathrm{E}-11$ & $1.84 \mathrm{E}-09$ \\
\hline SPLA50 $10 \mathrm{Cl}$ & 40 & 20.0 & 2 & 15.71 & $2.07 \mathrm{E}-10$ & $1.83 \mathrm{E}-09$ \\
\hline SPLA70 & 40 & 20.0 & 2 & 12.46 & $6.95 \mathrm{E}-11$ & $1.39 \mathrm{E}-09$ \\
\hline SPLA70 $10 \mathrm{Cl}$ & 40 & 20.0 & 2 & 18.0 & $1.51 \mathrm{E}-10$ & $1.59 \mathrm{E}-09$ \\
\hline
\end{tabular}
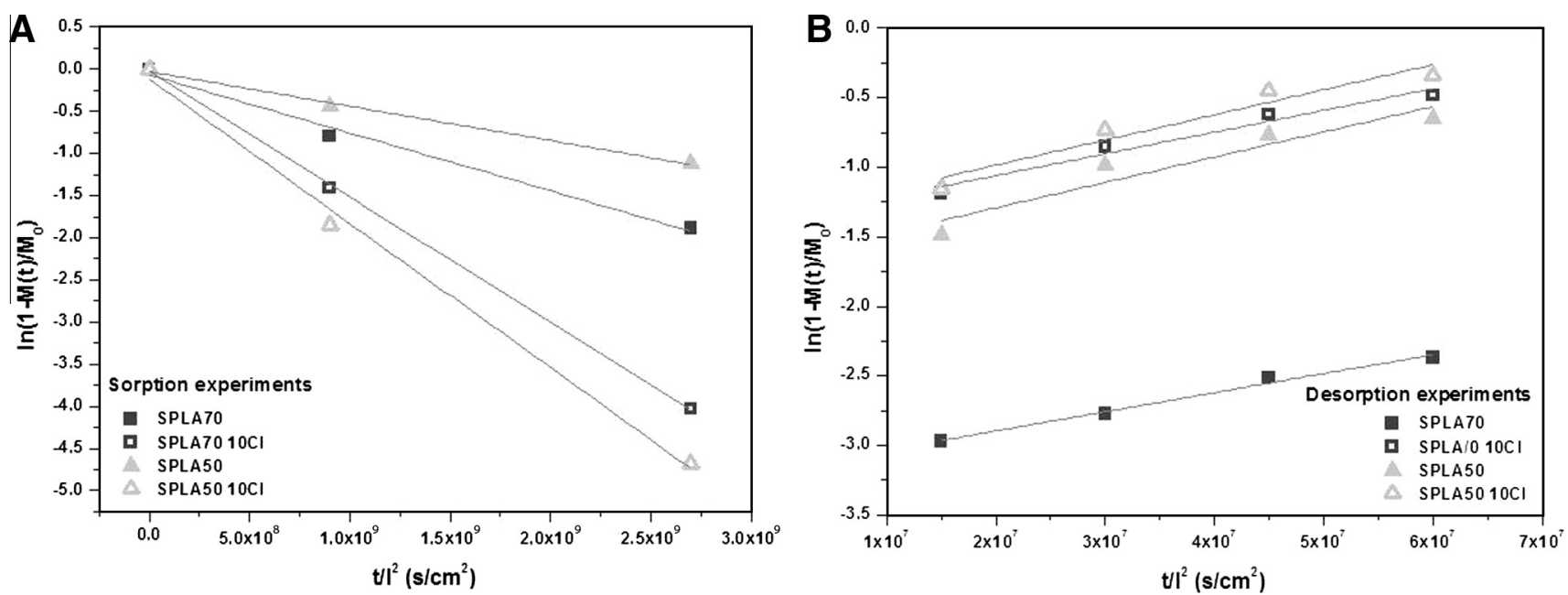

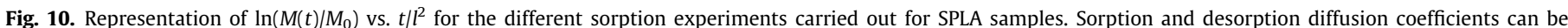
determined using the slope of the results represented in (A) and (B), respectively, and Eq. (4). 
with its crystallinity) and on the apparent diffusion coefficient of the solute in the polymer. The lower crystallinity of SPLA50 regarding SPLA70, and the lower desorption coefficient of supercritical $\mathrm{CO}_{2}$ in SPLA50 justify the high porosity obtained in the foaming of SPLA50 compared with SPLA70.

\section{Acknowledgments}

The research leading to these results has received funding from Fundação da Ciência e Tecnologia (FCT) through the project ENIGMA - PTDC/EQU-EPR/121491/2010 and from the European Union's Seventh Framework Programme (FP7/2007-2013) under Grant Agreement No. REGPOT-CT2012-316331-POLARIS. Marta Martins and Rita Craveiro are grateful for financial support from Fundação da Ciência e Tecnologia (FCT) through the Grants BIM/PTDC/ EQUEPR/121491/2010/ENIGMA and PTDC/EQUEPR/12191/2010/ ENIGMA.

\section{References}

[1] E. Chiellini, R. Solaro, Biodegradable polymeric materials, Adv. Mater. 8 (4) (1996) 305-313.

[2] A.C. Albertsson, S. Karlsson, Degradable polymers for the future, Acta Polym. 46 (2) (1995) 114-123.

[3] D.R. Lu, C.M. Xiao, S.J. Xu, Starch-based completely biodegradable polymer materials, Express Polym. Lett. 3 (6) (2009) 366-375.

[4] M.E. Zakrzewska, E. Bogel-Łukasik, R. Bogel-Łukasik, Solubility of carbohydrates in ionic liquids, Energy Fuels 24 (2) (2010) 737-745.

[5] C. Jun, Reactive blending of biodegradable polymers: PLA and starch, J. Polym. Environ. 8 (1) (2000) 33-37.

[6] L.J.M. Jacobs, M.F. Kemmere, J.T.F. Keurentjes, Sustainable polymer foaming using high pressure carbon dioxide: a review on fundamentals, processes and applications, Green Chem. 10 (7) (2008) 731-738.

[7] G.M. Schneider, Carbon Dioxide - International Thermodynamic Tables of the Fluid State, Bd. 3. Von S. Angus, B. Armstrong und K. M. de Rerrck. Pergamon Press Ltd., Oxford-New York 1976. 1. Aufl., XXVII, 385 S., zahlr. Abb. u. Tab., geb., DM 172,50, Chem. Ing. Tech. 49 (7) (1977) (p. 594-594).

[8] S. Keskin et al., A review of ionic liquids towards supercritical fluid applications, J. Supercrit. Fluids 43 (1) (2007) 150-180.

[9] S. Zhu et al., Dissolution of cellulose with ionic liquids and its application: a mini-review, Green Chem. 8 (4) (2006) 325-327.

[10] H. Xie, S. Zhang, S. Li, Chitin and chitosan dissolved in ionic liquids as reversible sorbents of CO2, Green Chem. 8 (7) (2006) 630-633.

[11] A. Sankri et al., Thermoplastic starch plasticized by an ionic liquid, Carbohydr. Polym. 82 (2) (2010) 256-263.
[12] O.A. El Seoud et al., Applications of Ionic liquids in carbohydrate chemistry: a window of opportunities, Biomacromolecules 8 (9) (2007) 2629-2647.

[13] A.R.C. Duarte et al., Ionic liquids as foaming agents of semi-crystalline naturalbased polymers, Green Chem. 14 (7) (2012) 1949-1955.

[14] L.N. Nikitin et al., Swelling and impregnation of polystyrene using supercritical carbon dioxide, J. Supercrit. Fluids 26 (3) (2003) 263-273.

[15] J.H. Aubert, Solubility of carbon dioxide in polymers by the quartz crysta microbalance technique, J. Supercrit. Fluids 11 (3) (1998) 163-172.

[16] C. Cravo, A.R.C. Duarte, C.M.M. Duarte, Solubility of carbon dioxide in a natura biodegradable polymer: determination of diffusion coefficients, J. Supercrit. Fluids 40 (2) (2007) 194-199.

[17] A.R.C. Duarte et al., Sorption and diffusion of dense carbon dioxide in a biocompatible polymer, J. Supercrit. Fluids 38 (3) (2006) 392-398.

[18] N.H. Brantley, S.G. Kazarian, C.A. Eckert, In situ FTIR measurement of carbon dioxide sorption into poly(ethylene terephthalate) at elevated pressures, J. Appl. Polym. Sci. 77 (4) (2000) 764-775.

[19] A.R.C. Duarte et al., A comparison between gravimetric and in situ spectroscopic methods to measure the sorption of $\mathrm{CO}_{2}$ in a biocompatible polymer, J. Supercrit. Fluids 36 (2) (2005) 160-165.

[20] A.R. Berens et al., Application of compressed carbon dioxide in the incorporation of additives into polymers, J. Appl. Polym. Sci. 46 (2) (1992) $231-242$.

[21] L. Avérous, Biodegradable Multiphase Systems Based on Plasticized Starch: A Review, J. Macromol. Sci. Part C 44 (3) (2004) 231-274.

[22] V. Chiono et al., Characterisation of blends between poly( $\varepsilon$-caprolactone) and polysaccharides for tissue engineering applications, Mater. Sci. Eng. C 29 (7) (2009) 2174-2187.

[23] S. Kang et al., A Spectroscopic analysis of poly (lactic acid) structure Macromolecules 34 (13) (2001) 4542-4548.

[24] M.B. Shiflett et al., Phase behavior of carbon dioxide+[bmim][Ac] mixtures, J Chem. Thermodyn. 40 (1) (2008) 25-31.

[25] J.F. Mano, D. Koniarova, R.L. Reis, Thermal properties of thermoplastic starch/ synthetic polymer blends with potential biomedical applicability, J. Mater. Sci. - Mater. Med. 14 (2) (2003) 127-135.

[26] E.W. Fischer, H.J. Sterzel, G. Wegner, Investigation of structure of solution grown crystals of lactide copolymers by means of chemical-reactions, Kolloid. Z. Z. Polym. 251 (11) (1973) 980-990.

[27] S. Jacobsen, H.G. Fritz, Plasticizing polylactide-The effect of different plasticizers on the mechanical properties, Polym. Eng. Sci. 39 (7) (1999) $1303-1310$.

[28] S.S. Silva et al., Green processing of porous chitin structures for biomedical applications combining ionic liquids and supercritical fluid technology, Acta Biomater. 7 (3) (2011) 1166-1172.

[29] X. Liao, A.V. Nawaby, P.S. Whitfield, Carbon dioxide-induced crystallization in poly(L-lactic acid) and its effect on foam morphologies, Polym. Int. 59 (12) (2010) 1709-1718.

30] J. Crank, Diffusion in Polymers, Academic Press, London, 1968.

[31] H.T., J., Studies of Sorption and Modification of Polymer Films in Supercritical Carbon Dioxide, University of Copenhagen, 2002. 